\title{
COP1 is downregulated in renal cell carcinoma (RCC) and inhibits the migration of RCC ACHN cells in vitro
}

\author{
LA TA $^{1}$, CHENGRUI XUAN ${ }^{2}$, NIANZENG XING ${ }^{1}$ and XIAOJUN ZHU ${ }^{3}$ \\ ${ }^{1}$ Department of Urology, Beijing Chao-Yang Hospital, Capital Medical University, Beijing 100020; \\ ${ }^{2}$ Department of Pathophysiology, Inner Mongolia Medical University, Hohhot, Inner Mongolia 010110; \\ ${ }^{3}$ Department of Urology, The First Affiliated Hospital of Inner Mongolia Medical University, \\ Hohhot, Inner Mongolia 010059, P.R. China
}

Received May 26, 2015; Accepted May 9, 2016

DOI: $10.3892 / \mathrm{mmr} .2016 .5373$

\begin{abstract}
Constitutive photomorphogenic 1 (COP1) belongs to the COP-de-etiolated (DET)-fusca (FUS) protein family and has been demonstrated to suppress prostate adenocarcinomas and other types of tumor, such as liver and gastric cancer. The present study investigated the expression of COP1 and its downstream factor, ets variant 1 (ETV1) in renal cell carcinoma (RCC) tissue samples, and evaluated the correlation of COP1 expression levels with the clinicopathological characteristics of RCC. In addition, the role of COP1 in the proliferation and migration of RCC ACHN cells was investigated. The results demonstrated significantly downregulated COP1 expression levels in the RCC intratumors, which was negatively associated with clinicopathological characteristics, such as tumor size, tumor-node-metastasis (TNM) stage and lymph node or distant metastasis. COP1 was demonstrated to markedly reduce the colony size of RCC ACHN cells, and inhibit the migration and invasion of ACHN cells. In addition, ETV1 and matrix metalloproteinase 7 (MMP7) mRNA and protein expression levels were significantly downregulated by the overexpressed COP1. Thus, the results of the present study demonstrate the reduced expression of COP1 and the upregulated expression of ETV1 in RCC tissue samples, which was associated with a high tumor-node-metastasis stage of RCC. Furthermore, the overexpression of COP1 in the RCC ACHN cells inhibited the migration and invasion of ACHN cells, and downregulated ETV1 and MMP7 expression levels. The present study demonstrated the tumor suppressive role of COP1 in RCC by inhibiting cell migration.
\end{abstract}

Correspondence to: Dr Nianzeng Xing, Department of Urology, Beijing Chao-Yang Hospital, Capital Medical University, 8 Gongti Nan Road, Chaoyang, Beijing 100020, P.R. China

E-mail: nianzen2006@sina.com

Key words: renal cell carcinoma, constitutive photomorphogenic 1, migration, matrix metalloproteinase 7

\section{Introduction}

Renal cell carcinoma ( RCC) is a lethal urological cancer $(1,2)$ and accounts for $\sim 3 \%$ of all adult malignancies worldwide (3). RCC is generally asymptomatic and $>70 \%$ of RCCs are discovered incidentally during an ultrasound or an abdominal scan requested for other diseases. Due to the rareness of biomarkers in the early diagnosis of RCC, $>20 \%$ of patients with RCC exhibit distant metastasis at their first diagnosis (4). Furthermore, RCC is resistant to radiation therapy and chemotherapy, which are usually effective for other types of adult malignancy. Surgery is the first choice of treatment for the early or intermediate stage of RCC. However, $30 \%$ of the patients undergoing nephrectomy for clinically localized RCC develop relapse at distant sites (5). The 5-year survival rate is $65-90 \%$ in cases without cancer metastasis; however, this is reduced in cases where the cancer has metastasized (6).

Numerous biomarkers have been recognized as prognostic for RCC. Increased expression levels of colony stimulating factor-1 (7) and overexpressed Aurora A (8) are predictors of poor prognosis in patients with clear-cell RCC (7). In addition, RCCRT1, a long non-coding (lnc) RNA, has been correlated with the RCC prognosis, and demonstrated to promote migration and invasion of RCC cells (9). Furthermore, previous studies have investigated serum and urine biomarkers for RCC (10).

Constitutive photomorphogenic 1 (COP1) belongs to the COP-de-etiolated (DET)-fusca (FUS) protein family and has been identified as a tumor suppressor in mouse prostate adenocarcinomas (11), and liver (12) and gastric cancers (13). Previous studies confirmed that COP1 is deregulated in triple-negative breast cancers, and thus provides prognostic value for these types of cancer $(14,15)$. Multiple proteins, including c-Jun and PEA3 family members, have been identified as substrates for COP1 (16). In addition, COP1 has been confirmed to promote the degradation of E26 transformation-specific (ETS) family members, such as ets variant 1 (ETV1) (11). However, the underlying mechanism of the tumor suppression effect of COP1 remains unknown. In the present study, the expression levels of COP1 in RCC tissue samples were investigated and the correlation of COP1 expression levels with the clinicopathological characteristics of RCC were examined. Furthermore, the role 
of COP1 in the proliferation and migration of ACHN RCC cells was assessed. To the best of our knowledge, the current study is the first to indicate the tumor suppressive effect of COP1 in RCC.

\section{Materials and methods}

Cell lines, culture and treatment. In the present study, 49 RCC specimens and 49 peritumor specimens (control; $\geq 10 \mathrm{~mm}$ from the tumor edge) were obtained by surgical resection from patients who were pathologically confirmed for RCC, and admitted to the First Affiliated Hospital of Inner Mongolia Medical University (Hohhot, China) between 2011 and 2014. The ACHN human renal cell line was purchased from the American Type Culture Collection (Manassas, VA, USA). The cells were cultured in Gibco Eagle's minimum essential medium (EMEM; Thermo Fisher Scientific, Inc., Waltham, MA, USA) supplemented with $10 \%$ fetal bovine serum (FBS; Sijiqing, Hangzhou, China), 100 units/ml penicillin (CSPC Shijiazhuang Pharmaceutical Group, Shijiazhuang, China) and $100 \mathrm{mg} / \mathrm{ml}$ streptomycin (CSPC) in a humidified incubator under $5 \% \mathrm{CO}_{2}$ at $37^{\circ} \mathrm{C}$.

To overexpress COP1 in the ACHN cells, the COP1 coding sequence was amplified with a human COPI cDNA clone (HG19467-CM; Sinobiological, Beijing, China) as template, and with COP1-specific primer pairs (forward, 5'-TCTAAG CTTATGTCTGGTAGCCGCCAGGCC-3'; reverse, 5'-ATA GGATCCTCATACCAATTCTAGCACCT-3') under the following conditions: $95^{\circ} \mathrm{C}$ for $5 \mathrm{~min}, 35$ cycles of $95^{\circ} \mathrm{C}$ for $1 \mathrm{~min}, 56^{\circ} \mathrm{C}$ for $1 \mathrm{~min}$ and $72^{\circ} \mathrm{C}$ for $2 \mathrm{~min}$ followed by $72^{\circ} \mathrm{C}$ for $10 \mathrm{~min}$. Subsequently, this was cloned into the eukaryotic pcDNA3.1(+) vector (Invitrogen; Thermo Fisher Scientific, Inc.). The COP1-pcDNA3.1(+) and control pcDNA3.1(+) plasmids were transfected into the ACHN cells using Lipofectamine 2000 (Invitrogen; Thermo Fisher Scientific, Inc.). The COP1-positive, ACHN(COP1+), and the control, $\mathrm{ACHN}(\mathrm{Con})$, cell clones were selected in the presence of $1 \mathrm{mg} / \mathrm{ml} \mathrm{G} 418$ (Thermo Fisher Scientific, Inc.) and maintained in medium containing $0.7 \mathrm{mg} / \mathrm{ml} \mathrm{G} 418$. To knockdown the COP1 expression in the $\mathrm{ACHN}(\mathrm{COP} 1+)$ cells, 25 or $50 \mathrm{nM}$ COP1-specific small interfering (si)RNA, siRNA-COP1 or siRNA-Con (Santa Cruz Biotechnology, Inc., Dallas, TX, USA) was transfected with a HiPerFect Transfection Reagent (Qiagen, GmbH, Hilden, Germany) into the $\mathrm{ACHN}(\mathrm{COP} 1+$ ) cells to abrogate COP1 expression.

$R N A$ isolation and reverse transcription-quantitative polymerase chain reaction $(R T-q P C R)$. RCC intra-tumor and peritumor tissue samples were homogenized and centrifuged at $3,000 \mathrm{x} \mathrm{g}$ at $4^{\circ} \mathrm{C}$ for $15 \mathrm{~min}$ to remove the non-homogenized tissue fraction. Each homogenate and ACHN cell sample was subjected to the lysis buffer in the Oligotex Direct mRNA Midi/Maxi kit (Qiagen, $\mathrm{GmbH}$ ) for mRNA isolation and total mRNA isolation was performed according to the manufacturer's instructions. RT-qPCR was performed using the One-Step SYBR PrimeScript ${ }^{\text {TM }}$ RT-PCR kit II (Perfect Real Time; Takara, Tokyo, Japan) to evaluate COP1, ETV1, matrix metalloproteinase 7 (MMP7) and $\beta$-actin mRNA expression levels. Each reaction system ( $25 \mu \mathrm{l}$ for total volume) contained $12.5 \mu \mathrm{l}$ SYBR Green PCR Master Mix, $2 \mu 1$ template mRNA,

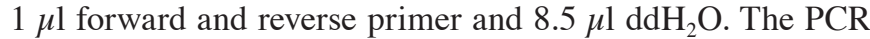
reaction was performed under the following conditions: An initial denaturation for $5 \mathrm{~min}$ at $95^{\circ} \mathrm{C}$, followed by 40 cycles of denaturation for $20 \mathrm{sec}$ at $94^{\circ} \mathrm{C}$, annealing for $20 \mathrm{sec}$ at $61^{\circ} \mathrm{C}$ and extension for $20 \mathrm{sec}$ at $72^{\circ} \mathrm{C}$, then a final extension for $5 \mathrm{~min}$ at $72^{\circ} \mathrm{C}$. The primer pairs (Sangon Biotech, Shanghai, China) were as follows: COP1, forward 5'-ATGAAATGA CCTGCAATTCG-3' and reverse 5'-TCACTGCTAGCTAAC AGGTTC-3'; ETV1, forward 5'-CATCCCAGCAGAACA GAAGG-3' and reverse 5'-CAGGTGTCATCATAAAAC TGC-3'; MMP7, forward 5'-TCATAGAAATAATGCAGA AGC-3' and reverse 5'-GTGAGTATTCTGCAACATCT-3'; $\beta$-actin, foward 5'-CATTAAGGAGAAGCTGTGCT-3' and reverse 5'-GTTGAAGGTAGTTTCGTGGA-3'. Data were normalized to $\beta$-actin and fold changes were calculated using the $2^{-\Delta \Delta \mathrm{Cq}}$ normalization method (17).

Protein isolation and western blot analysis. Western blot analysis was performed in RCC tissue specimens or ACHN cells to detect the protein levels of COP1, ETV1, MMP7 and $\beta$-actin. Briefly, each homogenized tissue sample or post-treated ACHN cell sample was lysed with ice-cold Cell Lysis Buffer (Cell Signaling Technology, Inc., Danvers, MA, USA) and was centrifuged at 9,000 $\mathrm{g}$ g for $30 \mathrm{~min}$ at $4^{\circ} \mathrm{C}$ to remove the cellular debris. Proteins $(25 \mu \mathrm{g})$ were separated by $12 \%$ SDS-PAGE gel (Sigma-Aldrich, St. Louis, MO, USA), and transferred to polyvinylidene fluoridehydrophobic membranes (EMD Millipore, Billerica, MA, USA), which were blocked with $2 \%$ bovine serum albumin (Ameresco, Inc., Framingham, MA, USA) at $4^{\circ} \mathrm{C}$ overnight. Subsequent to blocking, the membranes were incubated at $4^{\circ} \mathrm{C}$ for $2 \mathrm{~h}$ with rabbit polyclonal antibodies against COP1 (ab56400; 1:400; Abcam, Cambridge, UK), ETV1 (SAB2104467; 1:500; Sigma-Aldrich), MMP7 (AV46075; 1:500; Sigma-Aldrich) and $\beta$-actin (ab8227; Abcam) and washed three times. Following washes, the membranes were incubated with horseradish peroxidase-conjugated anti-rabbit IgG secondary antibody (7074; 1:1000; Cell Signaling Technology, Inc., Danvers, MA, USA) for $1 \mathrm{~h}$ at $4^{\circ} \mathrm{C}$ and washed three times. Finally, the specific binding band was detected with a chemiluminescent detection reagent (Amersham; GE Healthcare Life Sciences, Chalfont, UK). The relative expression levels for each protein were determined as a ratio to $\beta$-actin.

Cell counting and colony formation assays. The growth curve of $\mathrm{ACHN}(\mathrm{COP} 1+)$ and $\mathrm{ACHN}(\mathrm{Con})$ cells was determined using the cell counting assay (18). Briefly, ACHN(COP1+) or $\mathrm{ACHN}(\mathrm{Con})$ cells were seeded in 12-well plates and were incubated at $37^{\circ} \mathrm{C}$ for 24,48 or $72 \mathrm{~h}$. The cells were trypsinized and counted using a hemocytometer (Reicher, Buffalo, NY, USA) and trypan blue (Sigma-Aldrich). A colony formation assay was conducted to evaluate the growth of $\mathrm{ACHN}(\mathrm{COP} 1+)$ and $\mathrm{ACHN}(\mathrm{Con})$ cells. $\mathrm{ACHN}(\mathrm{COP} 1+)$ and $\mathrm{ACHN}(\mathrm{Con})$ cells were seeded into a 12 -well plate (200 cells/well) and 4 days later, the cell colonies were stained with $0.5 \%$ Crystal violet (Sigma-Aldrich) and counted directly by eye.

Migration and invasion assay. The migration and invasion capabilities of $\mathrm{ACHN}(\mathrm{COP} 1+)$ and $\mathrm{ACHN}(\mathrm{Con})$ cells were assessed using the scratch and transwell migration assays, 
Table I. Clinicopathological characteristics of patients with renal cell carcinoma.

Characteristic

Patients (n)
Fold-change of COP1

(mean \pm standard deviation)

P-value
Gender

Male

Female

Age (years)

$\begin{array}{ll}\leq 55 & 21 \\ >55 & 28\end{array}$

Size $(\mathrm{cm})$

$$
\leq 5.0
$$

$>5.0$

$$
19
$$

30

TNM stage

\section{I+II}

III+IV

27

22

21

28

$0.4612 \pm 0.0481$

0.485

$0.4816 \pm 0.0502$

$0.4279 \pm 0.0432$
$0.5023 \pm 0.0534$

0.006

$0.5791 \pm 0.0623$

$0.4016 \pm 0.0452$

$0.4992 \pm 0.0516$

$0.3815 \pm 0.0412$

ymph node metastasis
Yes
17
$0.3903 \pm 0.0413$
No
32
$0.5129 \pm 0.0530$

0.023

Distant metastasis

$\begin{array}{lll}\text { Yes } & 15 & 0.3982 \pm 0.0413 \\ \text { No } & 34 & 0.5023 \pm 0.0562\end{array}$

*TNM stage, tumor-node-metastasis classification system (30). COP1, constitutive photomorphogenic 1.

A

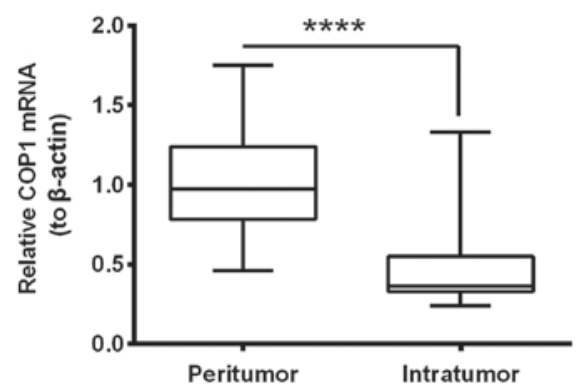

$\mathbf{C}$

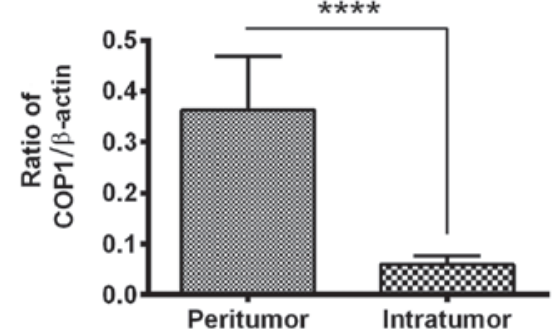

B

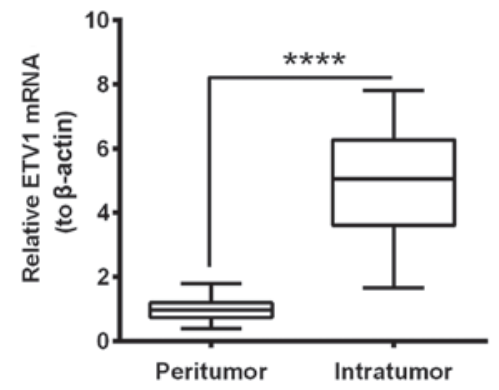

D

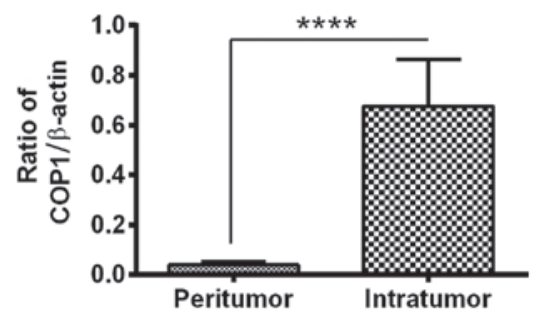

$\mathbf{E}$

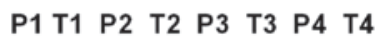

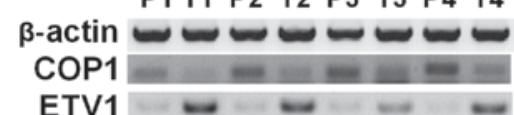

Figure 1. mRNA and protein expression levels of COP1 and ETV1 in RCC tissue samples. Relative mRNA levels of (A) COP1 and (B) ETV1 in the intratumor $(n=49)$ or peritumor $(n=49)$ tissue samples of RCC specimens, as assessed by reverse transcription-quantitative polymerase chain reaction. Relative protein expression levels of (C) COP1 and (D) ETV1 in the intratumor $(n=21)$ or peritumor $(n=21)$ tissue samples of RCC specimens, as assessed by (E) western blot analysis. ${ }^{* * * *} \mathrm{P}<0.0001$. RCC, renal cell carcinoma; COP1, constitutive photomorphogenic 1; ETV1, ets variant 1; P1-4, para-tumor specimen 1-4; T1-4, tumor specimen 1-4. 
A

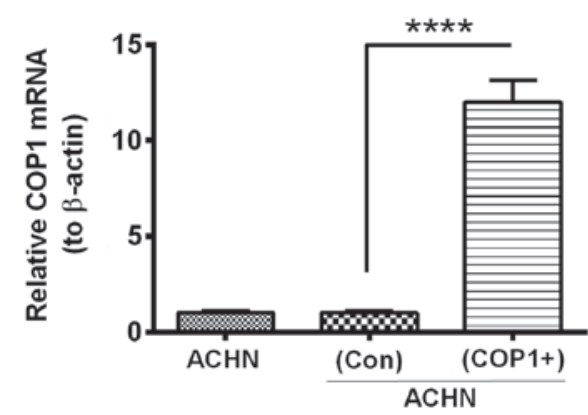

C

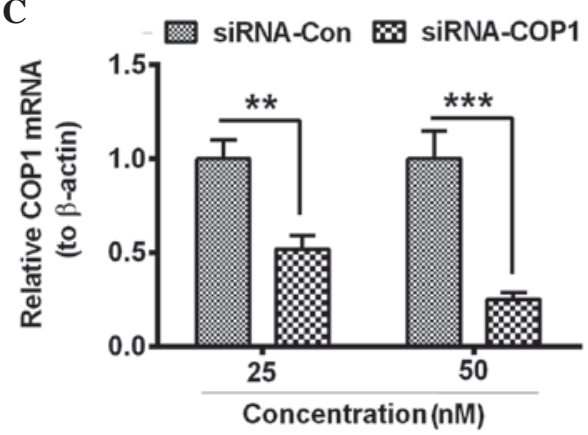

$\mathbf{E}$

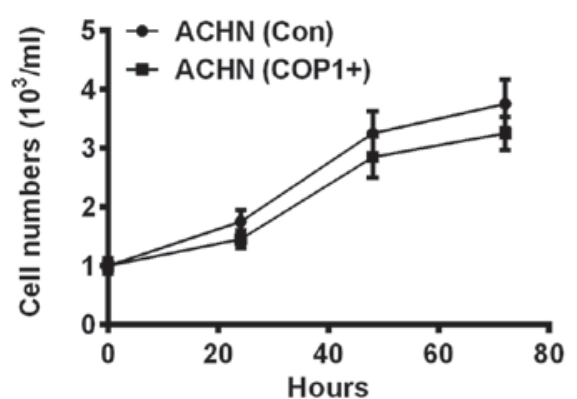

B

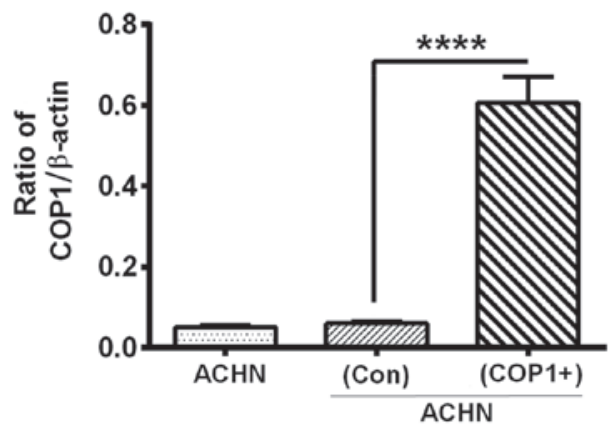

D

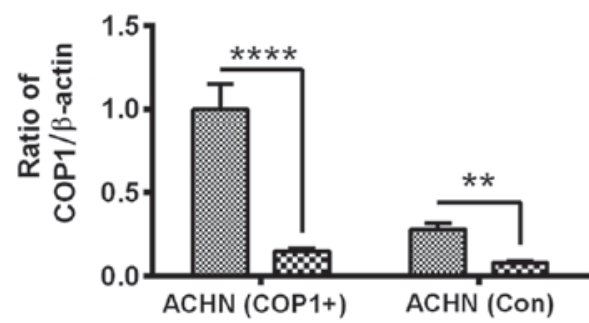

$\mathbf{F}$

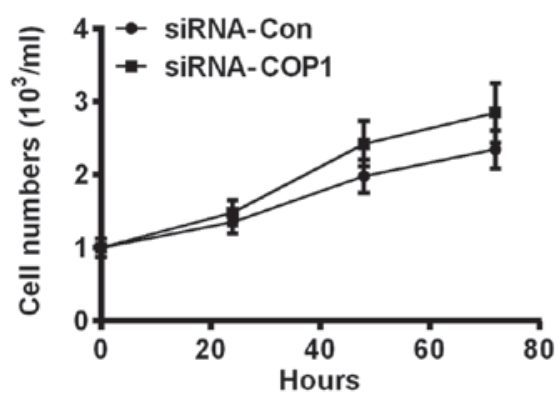

Figure 2. Influence of overexpressed COP1 on the proliferation of renal cell carcinoma ACHN cells. Relative (A) mRNA and (B) protein levels of COP1 in ACHN and in ACHN cells transfected with Con pcDAN3.1(+) or COP1-pcDAN3.1(+) plasmids (Con and COP1+, respectively). Relative COP1 (C) mRNA and (D) protein expression levels in ACHN cells transfected with COP1-specific siRNA (siRNA-COP1) or with Con siRNA (siRNA-Con). Growth curves of (E) ACHN(Con) and ACHN(COP1+), and (F) siRNA-Con and siRNA-COP1 cells ( $\mathrm{n}=3) .{ }^{* *} \mathrm{P}<0.01,{ }^{* * *} \mathrm{P}<0.001$ and ${ }^{* * * *} \mathrm{P}<0.0001$. COP1, constitutive photomorphogenic 1; Con, control; siRNA, small interfering RNA.

respectively. For the scratch assay, $\mathrm{ACHN}(\mathrm{COP} 1+)$ and $\mathrm{ACHN}(\mathrm{Con})$ cells were grown in 6-well plates and, upon reaching $90 \%$ confluency, the plates were scratched using a $200-\mu 1$ pipette tip. The healing process of the ACHN(COP1+) and $\mathrm{ACHN}(\mathrm{Con})$ cells was observed daily, and the migratory cells that crossed the wound area were counted at $48 \mathrm{~h}$ post inoculation. For the invasion assay, the experimental procedure followed was the same as the scratch assay. Briefly, cells were seeded $\left(1 \times 10^{5}\right.$ cells) on the upper transwell chamber with the non-coated membrane $(8-\mu \mathrm{m}$ pore size; Merck Millipore, Darmstadt, Germany). Once the cells had grown to $2 \times 10^{5}$ cells, they were coated with Matrigel (Sigma-Aldrich) and the lower chamber contained EMEM media with $20 \%$ FBS as a chemoattractant. The cells in the upper chamber were discarded after $24 \mathrm{~h}$ and the migratory cells in the lower chamber were counted using a microscope (BX60; Olympus Corporation, Tokyo, Japan). All the experiments were repeated in triplicate.
Statistical analysis. Statistical analysis was performed by unpaired t-test, using the Graphpad Prism software, version 5 (GraphPad Software, La Jolla, CA, USA) and $\mathrm{P}<0.05$ was considered to indicate a statistically significant difference.

\section{Results}

Reduced COP1 and upregulated ETVI mRNA and protein expression levels in RCC tissue samples are associated with tumor malignancy. To investigate the role of COP1 and its downstream factor, ETV1 in RCC, the expression levels of the two markers were determined in 49 RCC specimens. The RT-qPCR analysis indicated that the mRNA expression level of COP1 was significantly lower in the intratumor tissue samples $(0.4704 \pm 0.0530)$ compared with the peritumor tissue samples $(1.000 \pm 0.1208)$ of RCC (Fig. 1A; P<0.0001). The ETV1 mRNA levels were significantly increased in the intratumor tissue samples $(4.931 \pm 0.637)$ when compared with 
A

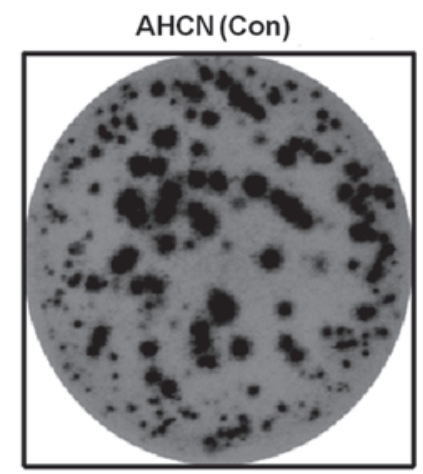

C

C
B

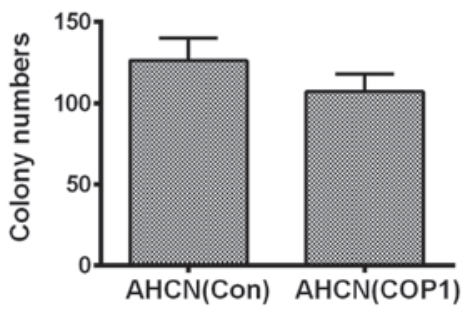

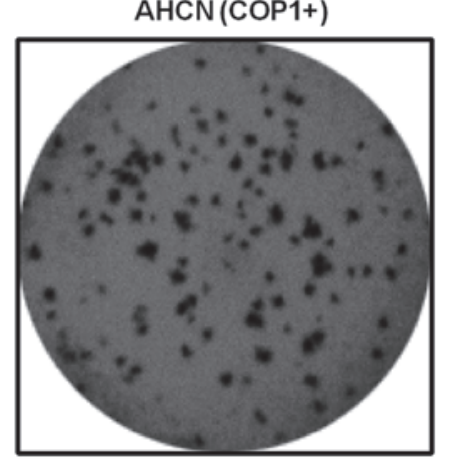

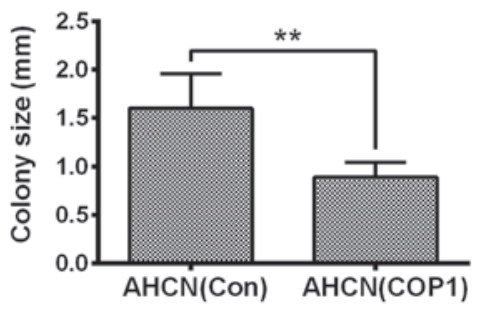

Figure 3. Influence of overexpressed COP1 on the colony formation of renal cell carcinoma ACHN cells. (A) Colonies formed by ACHN cells transfected with Con pcDAN3.1(+) or COP1-pcDAN3.1(+) plasmids $[\mathrm{AHCN}(\mathrm{Con})$ and $\mathrm{AHCN}(\mathrm{COP} 1+)$, respectively] 4 days post inoculation. ACHN(COP1+) and $\mathrm{ACHN}(\mathrm{Con})$ cell colony (B) number and (C) size are presented. The mean was calculated from three independent experiments. * $\mathrm{P}<0.01$. Con, control; COP1, constitutive photomorphogenic 1.

A

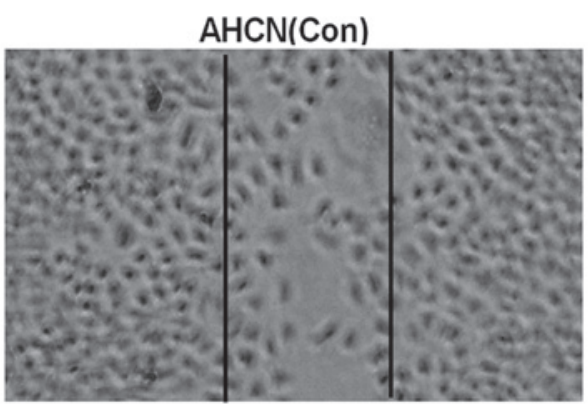

B

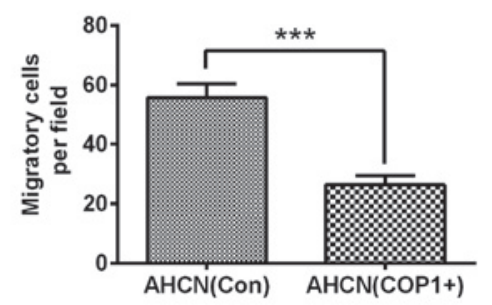

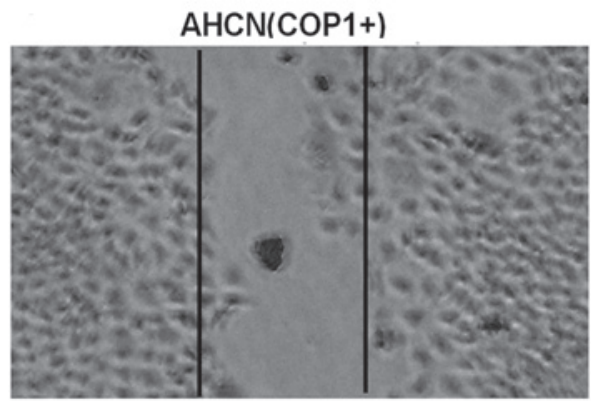

C

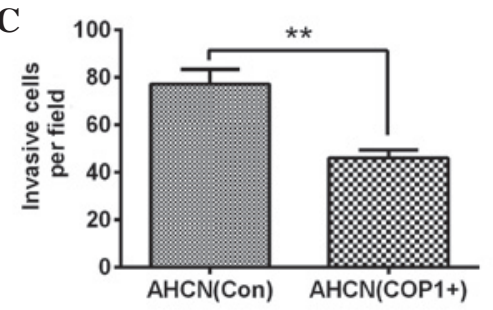

Figure 4. Overexpressed COP1 inhibits the cell migration and invasion of renal cell carcinoma ACHN cells. (A) Representative migration of ACHN cells transfected with Con pcDAN3.1(+) or COP1-pcDAN3.1(+) plasmids [AHCN(Con) and AHCN(COP1+), respectively] as determined by scratch assay. (B) Number of migratory cells across the scratch wound in the $\mathrm{ACHN}(\mathrm{Con})$ and $\mathrm{ACHN}(\mathrm{COP} 1+)$ groups. (C) Number of invasive cells that crossed the Matrigel-coated filter as assessed by a Matrigel-coated transwell assay. Data are presented as the mean \pm standard error of the mean $(\mathrm{n}=3) .{ }^{* *} \mathrm{P}<0.01$ and ${ }^{* * *} \mathrm{P}<0.001$. Con, control; COP1, constitutive photomorphogenic 1 .

the peritumor tissue samples $(1.000 \pm 0.120)$ of RCC (Fig. 1B; $\mathrm{P}<0.0001)$. The down- and upregulated expression levels of COP1 and ETV1, respectively, were also confirmed at the protein level by western blot analysis $(\mathrm{P}<0.0001$; Fig. 1C-E).

Association of COPI expression with the clinicopathological characteristics of RCC patients. As demonstrated in Table I, no significant association was observed between gender or age and COP1 expression level in patients with RCC. However,
COP1 expression was negatively associated with the tumor size ( $\mathrm{P}=0.006)$, tumor-node-metastasis (TNM) stage $(\mathrm{P}=0.012)$, lymph node metastasis $(\mathrm{P}=0.010)$ and distant metastasis $(\mathrm{P}=0.023$; Table I). The COP1 expression level in patients with larger tumors $(>5 \mathrm{~cm})$, lymph node metastasis, increased TNM stage or distant metastasis was significantly lower (Table I).

Influence of COP1 overexpression on the growth of RCC AHCN cells. To further investigate the role of COP1 in the 

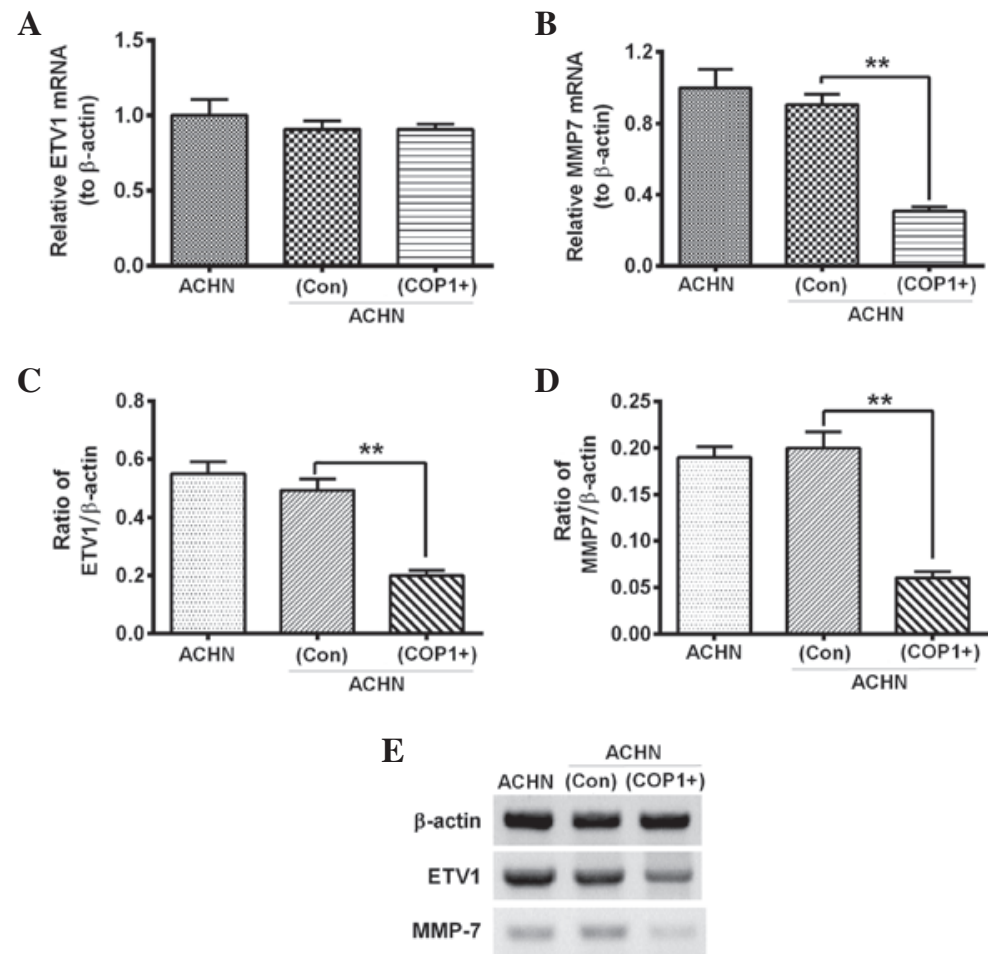

Figure 5. Overexpressed COP1 inhibits the mRNA and protein expression levels of ETV1 and MMP7 in renal cell carcinoma ACHN cells. Relative mRNA expression levels of (A) ETV1 and (B) MMP7 in ACHN, and ACHN cells transfected with Con pcDAN3.1(+) or COP1-pcDAN3.1(+) plasmids [AHCN(Con) and $\mathrm{AHCN}(\mathrm{COP} 1+)$, respectively]. Relative protein expression levels of (C) ETV1 and (D) MMP7 as assessed by (E) western blotting in ACHN, AHCN(Con) and $\mathrm{AHCN}(\mathrm{COP} 1+)$ cells $(\mathrm{n}=3) .{ }^{* *} \mathrm{P}<0.01$. ETV1, ets variant 1; Con, control; MMP7, matrix metalloproteinase 7.

RCC cells, COP1 was overexpressed via a eukaryotic vector, pcDNA3.1(+). The coding sequence of COP1 was cloned into pcDNA3.1(+) and the recombinant plasmid was transfected into the AHCN cells. As demonstrated in Fig. 2A and B, the relative COP1 mRNA and protein levels were significantly increased in the AHCN cells transfected with the recombinant COP1-pcDAN3.1(+) plasmid compared with the AHCN(Con) cells $(\mathrm{P}<0.0001)$. The effect of COP1 on the growth of RCC AHCN cells was investigated by silencing COP1 expression. To knockdown COP1, AHCN(COP1+) cells were transfected with COP1-specific siRNA (siRNA-COP1). As demonstrated in Fig. 2C, the relative mRNA levels of COP1 were significantly reduced by transfection with 25 and $50 \mathrm{nM}$ siRNA-COP1 compared with the siRNA-Con $(\mathrm{P}<0.01$ and $\mathrm{P}<0.001$, respectively). As demonstrated in Fig. $2 \mathrm{D}$, the relative protein levels of COP1 were significantly reduced by the siRNA-COP1 transfection compared with the siRNA-Con in the $\mathrm{AHCN}(\mathrm{COP} 1+)$ and $\mathrm{AHCN}(\mathrm{Con})$ groups $(\mathrm{P}<0.0001$ and $\mathrm{P}<0.01$, respectively).

Following establishment of a successful knockdown model, the influence of COP1 overexpression on the growth of RCC AHCN cells was assessed using cell counting and colony formation assays. AHCN(COP1+) and AHCN(Con) cells were seeded with an initial titer of $10^{3}$ cells $/ \mathrm{ml}$ in 12 -well plates, and the cell number was counted every $24 \mathrm{~h}$ post-seeding. In a separate experiment, the seeded cells were transfected with siRNA-COP1 or siRNA-Con and the cell numbers were counted. As demonstrated in Fig. 2E, the titer of the AHCN(COP1+) cells was lower when compared with the $\mathrm{AHCN}(\mathrm{Con})$ cells; however, no significant difference was identified between the two groups. Furthermore, the transfection of siRNA-COP1 did not significantly influence the proliferation of $\mathrm{AHCN}(\mathrm{COP} 1+)$ cells (Fig. 2F; P>0.05). In addition, the overexpression of COP1 did not demonstrate a significant change in the colony numbers of AHCN cells (Fig. 3A and B). However, COP1 overexpression resulted in a significantly reduced colony size when compared with those of the AHCN(Con) group (Fig. 3C; $\mathrm{P}<0.05$ ). These data indicate that COP1 overexpression exerts a limited influence on the growth of RCC cells.

COPl overexpression inhibits the migration of RCC AHCN cells in vitro. It has been proposed that cell migration contributes to tumor metastasis (19). To further investigate the regulatory role of $\mathrm{COP} 1$ in the progression of $\mathrm{RCC}$, the migration of $\mathrm{AHCN}(\mathrm{COP} 1+)$ and $\mathrm{AHCN}(\mathrm{Con})$ cells was assessed via scratch assay. The results demonstrated fewer migratory cells in the AHCN(COP1+) group when compared with the AHCN(Con) group (Fig. 4A and $\mathrm{B} ; \mathrm{P}<0.001)$. To further evaluate the invasion of $\mathrm{AHCN}(\mathrm{COP} 1+)$ and $\mathrm{AHCN}(\mathrm{Con})$ cells, the Matrigel-coated transwell assay was utilized. The results demonstrated a reduced number of invasive cells per field in the $\mathrm{AHCN}(\mathrm{COP} 1+)$ group when compared with the AHCN(Con) group (Fig. 4C; $\mathrm{P}<0.01$ ). The results from the assays indicated that $\mathrm{COP} 1$ overexpression reduced the migration and invasion of RCC cells in vitro.

Overexpressed COP1 reduces $M M P 7$ via the degradation of ETV1 in RCC AHCN cells. COP1 has been indicated to promote the degradation of ETV1 (14). To deduce the inhibition to the migration of AHCN cells by overexpressed COP1, the ETV1 and MMP7 expression levels in the AHCN(COP1+) 
and $\mathrm{AHCN}(\mathrm{Con})$ cells were assessed. No significant difference was observed in the ETV1 mRNA expression levels between the $\mathrm{AHCN}(\mathrm{COP} 1+)$ and $\mathrm{AHCN}(\mathrm{Con})$ groups (Fig. 5A; $\mathrm{P}<0.05)$. However, the MMP7 mRNA expression levels were significantly downregulated in the $\mathrm{AHCN}(\mathrm{COP} 1+)$ group compared with the AHCN(Con) group (Fig. 5B; $\mathrm{P}<0.01$ ). Furthermore, the protein levels of the two markers were significantly downregulated in the $\mathrm{AHCN}(\mathrm{COP} 1+)$ group compared with the $\mathrm{AHCN}(\mathrm{Con})$ group (Fig. 5C-E; $\mathrm{P}<0.01$ ). These data indicate that MMP7 is significantly inhibited by the overexpression of COP1.

\section{Discussion}

The present study investigated the expression of COP1 in RCC cells and demonstrated that the mRNA and protein expression levels of COP1 were significantly downregulated in $49 \mathrm{RCC}$ tissue samples. ETV1, the targeting marker of COP1, was significantly upregulated in these 49 RCC specimens. Despite being deregulated in other types of tumor, such as prostate adenocarcinomas (11), and liver (12) and gastric (13) cancers, as well as being associated with the prognosis of these types of tumor, the exact role of COP1 in tumorigenesis is not fully understood. The present study indicated that the overexpression of COP1 in RCC ACHN cells did not have a regulatory effect on the growth of ACHN cells, implying only a marginal influence on the proliferation of RCC cells. However, the colony formation assay demonstrated that COP1 significantly inhibited the size of the colonies formed by ACHN cells. In addition, the scratch and transwell assays confirmed the significant inhibitory effect of COP1 on ACHN cell migration and invasion.

COP1 belongs to the COP-DET-FUS protein family, possesses E3 ubiquitin ligase activity and is involved in the ubiquitylation of various protein substrates to trigger their proteasomal degradation (20). The ubiquitin ligase, COP1 negatively regulates ETV1, 4 and 5 via degrading ubiquitinated ETVs in prostate epithelial cells (11). COP1 has been recognized to regulate the stability and the transcriptional activity of PEA3 factor, which is dependent on the RING finger domain of COP1 (21). In the present study, a upregulated ETV1 in the mRNA and protein levels was demonstrated in the 49 RCC specimens, which was associated with downregulated COP1 expression. Furthermore, the in vitro experiments confirmed the downregulation of ETV1 by COP1 in the ACHN cells. These findings indicate that the downregulated ETV1 expression may have contributed to the reduced migration and invasion of the ACHN cells. This further implies that reduced COP1 expression and the upregulated ETV1 may contribute to the aggressive nature of RCC cells in vivo.

MMP7 is a zinc- and calcium-dependent endopeptidase that cleaves a broad range of extracellular matrix macromolecules, such as fibronectin, laminin, proteoglycan, elastin, gelatin, type IV collagen and 1-antitrypsin $(22,23)$. The overexpression of MMP7 has been reported in numerous types of cancerous tissue, such as colorectal (24), ovarian (25) and pancreatic (26) cancer. Furthermore, an increased expression level of MMP7 was demonstrated in high-grade RCC tumors (27). A previous study demonstrated that ETV1 bound to the MMP7 gene promoter and stimulated MMP7 expression (28). The present study demonstrated that overexpressed COP1 reduced the MMP7 expression levels, along with the downregulation of ETV1. Thus, the reduced expression levels of MMP7 may contribute to the reduced migration of ACHN cells that overexpressed COP1.

In conclusion, the current study confirmed the reduced expression of COP1, along with the upregulated ETV1 in the RCC tissue specimens, which was associated with a high TNM stage of RCC. In addition, the overexpression of COP1 in the RCC ACHN cells inhibited the migration and invasion of the ACHN cells, and downregulated the expression levels of ETV1 and MMP7. Thus, the present study confirmed the tumor suppressive role of COP1 in RCC via inhibiting cell migration, and suggests that COP1 may be a valuable target for the anti-cancer treatment of RCC.

\section{References}

1. Rini BI, Campbell SC and Escudier B: Renal cell carcinoma. Lancet 373: 1119-1132, 2009.

2. Rini BI, Rathmell WK and Godley P: Renal cell carcinoma. Curr Opin Oncol 20: 300-306, 2008

3. Motzer RJ, Bander NH and Nanus DM: Renal-cell carcinoma. N Engl J Med 335: 865-875, 1996.

4. Itsumi $\mathrm{M}$ and Tatsugami K: Immunotherapy for renal cell carcinoma. Clin Dev Immunol 2010: 284581, 2010.

5. Pantuck AJ, Zisman A and Belldegrun AS: The changing natural history of renal cell carcinoma. J Urol 166: 1611-1623, 2001

6. Singer EA, Gupta GN, Marchalik D and Srinivasan R: Evolving therapeutic targets in renal cell carcinoma. Curr Opin Oncol 25: 273-280, 2013.

7. Yang L, Wu Q, Xu L, Zhang W, Zhu Y, Liu H, Xu J and Gu J: Increased expression of colony stimulating factor- 1 is a predictor of poor prognosis in patients with clear-cell renal cell carcinoma. BMC Cancer 15: 67, 2015.

8. Ferchichi I, Kourda N, Sassi S, Romdhane KB, Balatgi S, Cremet JY, Prigent $C$ and Elgaaied AB: Aurora A overexpression and pVHL reduced expression are correlated with a bad kidney cancer prognosis. Dis Markers 33: 333-340, 2012.

9. Song S, Wu Z, Wang C, Liu B, Ye X, Chen J, Yang Q, Ye H, $\mathrm{Xu} \mathrm{B}$ and Wang L: RCCRT1 is correlated with prognosis and promotes cell migration and invasion in renal cell carcinoma. Urology 84(3): 730, 2014.

10. Pastore AL, Palleschi G, Silvestri L, Moschese D, Ricci S, Petrozza V, Carbone A and Di Carlo A: Serum and urine biomarkers for human renal cell carcinoma. Dis Markers 2015: 251403, 2015.

11. Vitari AC, Leong KG, Newton K, Yee C, O'Rourke K, Liu J, Phu L, Vij R, Ferrando R, Couto SS, et al: COP1 is a tumour suppressor that causes degradation of ETS transcription factors. Nature 474: 403-406, 2011.

12. Xu S, Tong M, Huang J, Zhang Y, Qiao Y, Weng W, Liu W, Wang J and Sun F: TRIB2 inhibits Wnt/ $\beta$-Catenin/TCF4 signaling through its associated ubiquitin E3 ligases, $\beta$-TrCP, COP1 and Smurf1, in liver cancer cells. FEBS Lett 588: 4334-4341, 2014.

13. Sawada G, Ueo H, Matsumura T, Uchi R, Ishibashi M, Mima K, Kurashige J, Takahashi Y, Akiyoshi S, Sudo T, et al: Loss of COP1 expression determines poor prognosisin patients with gastric cancer. Oncol Rep 30: 1971-1975, 2013.

14. Ouyang M, Wang H, Ma J, Lü W, Li J, Yao C, Chang G, Bi J, Wang S and Wang W: COP1, the negative regulator of ETV1, influences prognosis in triple-negative breast cancer. BMC Cancer 15: 132, 2015.

15. Shao J, Teng Y, Padia R, Hong S, Noh H, Xie X, Mumm JS, Dong Z, Ding HF, Cowell J, et al: COP1 and GSK3 $\beta$ cooperate to promote c-Jun degradation and inhibit breast cancer cell tumorigenesis. Neoplasia 15: 1075-1085, 2013.

16. Wei W and Kaelin WG Jr: Good COP1 or bad COP1? In vivo veritas. J Clin Invest 121: 1263-1265, 2011.

17. Livak KJ and Schmittgen TD: Analysis of relative gene expression data using real-time quantitative PCR and the 2(-Delta Delta C(T)) method. Methods 25: 402-408, 2001.

18. Li Z, Tian T, Lv F, Chang Y, Wang X, Zhang L, Li X, Li L, Ma W, Wu J and Zhang M: Six 1 promotes proliferation of pancreatic cancer cells via upregulation of cyclin D1 expression. PLoS One 8: e59203, 2013. 
19. Parkin DM, Bray F, Ferlay J and Pisani P: Global cancer statistics, 2002. CA Cancer J Clin 55: 74-108, 2005.

20. Marine JC: Spotlight on the role of COP1 in tumorigenesis. Nat Rev Cancer 12: 455-464, 2012.

21. Papoutsopoulou S and Janknecht R: Phosphorylation of ETS transcription factor ER81 in a complex with its coactivators CREB-binding protein and p300. Mol Cell Biol 20: 7300-7310, 2000

22. Murphy G, Cockett MI, Ward RV and Docherty AJ: Matrix metalloproteinase degradation of elastin, type IV collagen and proteoglycan. A quantitative comparison of the activities of $95 \mathrm{kDa}$ and $72 \mathrm{kDa}$ gelatinases, stromelysins- 1 and -2 and punctuated metalloproteinase (PUMP). Biochem J 277: 277-279, 1991.

23. Sires UI, Murphy G, Baragi VM, Fliszar CJ, Welgus HG and Senior RM: Matrilysin is much more efficient than other matrix metalloproteinases in the proteolytic inactivation of alpha 1-antitrypsin. Biochem Biophys Res Commun 204: 613-620, 1994.

24. Adachi Y, Yamamoto H, Itoh F, Arimura Y, Nishi M, Endo T and Imai K: Clinicopathologic and prognostic significance of matrilysin expression at the invasive front in human colorectal cancers. Int J Cancer 95: 290-294, 2001.
25. Tanimoto H, Underwood LJ, Shigemasa K, Parmley TH, Wang Y, Yan Y, Clarke J and O'Brien TJ: The matrix metalloprotease pump-1 (MMP-7, Matrilysin): A candidate marker/target for ovarian cancer detection and treatment. Tumour Biol 20: 88-98, 1999.

26. Yamamoto H, Itoh F, Iku S, Adachi Y, Fukushima H, Sasaki S, Mukaiya M, Hirata K and Imai K: Expression of matrix metalloproteinases and tissue inhibitors of metalloproteinases in human pancreatic adenocarcinomas: Clinicopathologic and prognostic significance of matrilysin expression. J Clin Oncol 19: 1118-1127, 2001.

27. Sumi T, Nakatani T, Yoshida H, Hyun Y, Yasui T, Matsumoto Y, Nakagawa E, Sugimura K, Kawashima $\mathrm{H}$ and Ishiko O: Expression of matrix metalloproteinases 7 and 2 in human renal cell carcinoma. Oncol Rep 10: 567-570, 2003.

28. Rahim S, Minas T, Hong SH, Justvig S, Çelik H, Kont YS, Han J, Kallarakal AT, Kong Y, Rudek MA et al: A small molecule inhibitor of ETV1, YK-4-279, prevents prostate cancer growth and metastasis in a mouse xenograft model. PLoS ONE 9: e114260, 2014 